\title{
Particle platforms for cancer immunotherapy
}

This article was published in the following Dove Press journal:

International Journal of Nanomedicine

26 April 2013

Number of times this article has been viewed

\author{
Rita Elena Serda \\ Department of Nanomedicine, \\ The Methodist Hospital Research \\ Institute, Houston, TX, USA
}

Correspondence: Rita E Serda Department of Nanomedicine, The Methodist Hospital Research Institute, 6670 Bertner Avenue, R7-I I2, Houston, TX 77030, USA

$\mathrm{Tel}+171344 \mid 7315$

$\mathrm{Fax}+\mid$ 7|3 44I 7537

Email reserda@tmhs.org

\begin{abstract}
Elevated understanding and respect for the relevance of the immune system in cancer development and therapy has led to increased development of immunotherapeutic regimens that target existing cancer cells and provide long-term immune surveillance and protection from cancer recurrence. This review discusses using particles as immune adjuvants to create vaccines and to augment the anticancer effects of conventional chemotherapeutics. Several particle prototypes are presented, including liposomes, polymer nanoparticles, and porous silicon microparticles, the latter existing as either single- or multiparticle platforms. The benefits of using particles include immune-cell targeting, codelivery of antigens and immunomodulatory agents, and sustained release of the therapeutic payload. Nanotherapeutic-based activation of the immune system is dependent on both intrinsic particle characteristics and on the immunomodulatory cargo, which may include danger signals known as pathogen-associated molecular patterns and cytokines for effector-cell activation.
\end{abstract}

Keywords: adjuvant, particle, immunotherapy, dendritic cell, cancer, vaccine

\section{Introduction}

Cancer remains a major cause of human morbidity and mortality, despite advances in our understanding of the etiological agents giving rise to cancer and mechanisms of oncogenesis. Cancer has many causes, and heterogeneity within cancer-cell populations makes targeting single pathways or cellular mutations unlikely to be fully curative. Further complicating therapeutic interventions are the realities that each cancer is unique in its pathophysiology and that cancer cells have the potential to adapt to survive. Our bodies normally safeguard us against cancer through immune surveillance and removal of abnormal cells as they arise. However, the combination of adaptation of cancer cells and immunosuppressive changes in the tumor microenvironment impairs normal immune functions. Boosting the immune response in the presence of appropriate cancer antigens is one approach to reactivating normal immune defense mechanisms. Nanoparticle platforms present a means to codeliver immune stimulants and either cancer antigens or agents that expose endogenous cancer antigens.

The role of the immune system in cancer detection and progression is complex, with immune surveillance providing monitoring for diseased or mutated cells, and a role for chronic inflammation in cancer initiation and progression. ${ }^{1,2}$ The role of inflammation in cancer initiation was first postulated in 1863 by Rudolph Virchow, who observed leukocyte infiltration in neoplastic tissues and proposed that malignant tumors arise at sites of chronic inflammation. ${ }^{3,4}$ Chronic inflammation and the presence of abundant inflammatory cells leads to oxidative damage and environmental changes that favor 
cellular transformation and proliferation..$^{5}$ Infiltrating leukocytes and macrophages enhance angiogenesis ${ }^{6}$ and exert profibrogenic events. ${ }^{7}$ Despite the prevalence of immune cells, the tumor microenvironment is immunosuppressive. Negative immune regulators include T-regulatory $\left(\mathrm{T}_{\text {reg }}\right)$ cells, myeloid-derived suppressor cells (MDSCs; CD11 b ${ }^{+}, \mathrm{Gr}-1^{+}$), and immunosuppressive cytokines (eg, interleukin [IL]-10) and growth factors (eg, transforming growth-factor [TGF]- $\beta$ ). Negative regulatory receptors include programmed death (PD)-1, cluster of differentiation (CD)-25, and cytotoxic T-lymphocyte antigen 4 (CTLA-4). An additional challenge in designing therapeutics is the dual role of some immune modulators, such as TGF- $\beta$, which can switch from tumor suppressor to tumor promoter. ${ }^{8}$

Complement is another immune regulator with a wide range of functions, including pathogen opsonization, killing of bacteria through lysis, and clearance of immune complexes and apoptotic cells..$^{9,10}$ It is thought to function as a bridge between innate and adaptive immunity. Complement is activated by sequential binding/recognition and cleavage events, with complement products, such as $\mathrm{C} 3 \mathrm{a}$, serving as inflammatory mediators and chemoattractants. ${ }^{8}$ Despite its positive immune regulation, complement has also been implicated in tumor progression, with pharmacological blockade of the $\mathrm{C} 5 \mathrm{a}$ receptor slowing tumor growth and enhancing $\mathrm{CD} 8^{+}$ T-cell antitumor responses. ${ }^{11}$ The $\mathrm{C} 5$ a blockade is thought to disrupt recruitment of MDSCs and induce functional hindrance of existing immune cells. In addition, C5a regulates the production of reactive oxygen and nitrogen species by MDSCs, contributing to immune suppression. ${ }^{8}$

Galluzzi et $\mathrm{al}^{12}$ recently published a comprehensive review on the ability of conventional chemotherapeutics to stimulate the immune system against cancer. Mechanisms of action included: direct T-cell activation leading to the production of IL-2, interferon (IFN)- $\gamma$, and IL-17; maturation and activation of dendritic cells (DCs); inhibition or depletion of MDSCs and $\mathrm{T}_{\text {reg }}$ cells; inhibition of signal transducer and activator of transcription 6 phosphorylation and PD ligand 2-mediated immunosuppression; enhanced permeability of tumor cells to granzyme; and altered expression of transcription factors, cytokines, and chemokines.

Certain chemotherapeutics, such as anthracyclines and platinum-based antineoplastic drugs, trigger the release of inflammatory danger signals. Example of these signals include adenosine triphosphate ${ }^{13}$ and high-mobility group box $1 .{ }^{14}$ These agents activate the inflammasome, leading to IL-1 $\beta$ secretion, and stimulate Toll-like receptors (TLRs) on DCs, respectively. Taxanes increase tumor-infiltrating lymphocytes and increase levels of T helper 1 (Th1)-associated cytokines while decreasing negative inflammatory agents. ${ }^{15,16}$ Cyclophosphamide, an alkylating agent, depletes immunosuppressive $\mathrm{T}_{\text {reg }}$ cells. ${ }^{17}$ Necrotic tumor cells, apoptotic bodies, and locally released tumor-associated antigens resulting from chemotherapy are then available for uptake by activated DCs, and the antigens are processed for presentation to lymphocytes. ${ }^{17}$

One goal for nanoparticle-based immunotherapy is to further antagonize the immunosuppressive environment to achieve effective immune responses. Immune adjuvants include agents that skew the tumor-microenvironment cytokine milieu. It has been demonstrated that patients with tumors that have strong Th1 cytotoxic T-lymphocyte (CTL) responses and high levels of infiltrating lymphocytes respond better to neoadjuvant chemotherapy than patients with tumors skewed towards Th2 responses. ${ }^{18,19}$ Depletion of $\mathrm{CD}^{+}$but not $\mathrm{CD}^{+} \mathrm{T}$ cells or NK cells in mice abolishes antitumor immune effects induced by combination chemotherapy and antigen exposure. ${ }^{20}$ An alternative to adjuvant therapy, and more difficult to accomplish, is the creation of prophylactic and therapeutic vaccines that function without the need for radiation or chemotherapeutics.

Major nanotechnology concepts presented in this review are illustrated in Figure 1. Particle platforms and properties that enhance their ability to function as adjuvants and vaccines are presented in Figure 1A. The influence of inherent particle properties, such as size, on antigen-presenting cell (APC) uptake and migration to the draining lymph node is presented in Figure 1B, and the processing and presentation of particledelivered antigens by DC are presented in Figure $1 \mathrm{C}$.

\section{Cancer vaccines and retraining the immune microenvironment}

The goal of prophylactic vaccines is activation and clonal expansion of B cells that secrete cancer-specific antibodies for opsonization of cancer cells leading to recognition by NK cells, monocytes, and macrophages (ie, antibody-dependent cell-mediated cytotoxicity). ${ }^{21}$ The goal of therapeutic vaccines is clonal expansion of cytolytic $\mathrm{T}$ cells that recognize cancer cells and induce cell death through the release of the perforin and granzyme. These cytotoxins create pores in the target cell's membrane and activate the caspase cascade, leading to apoptosis. The optimal cancer vaccine would activate both humoral and cellular arms of adaptive immunity, leading to cancer ablation and long-term immune surveillance through the establishment of tumor-specific effector and memory $\mathrm{T}$, $\mathrm{B}$, and plasma cells. 


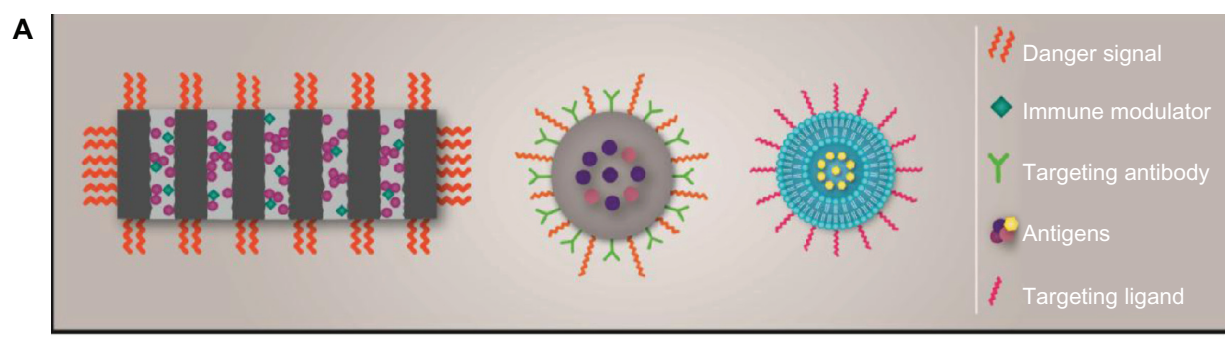

B

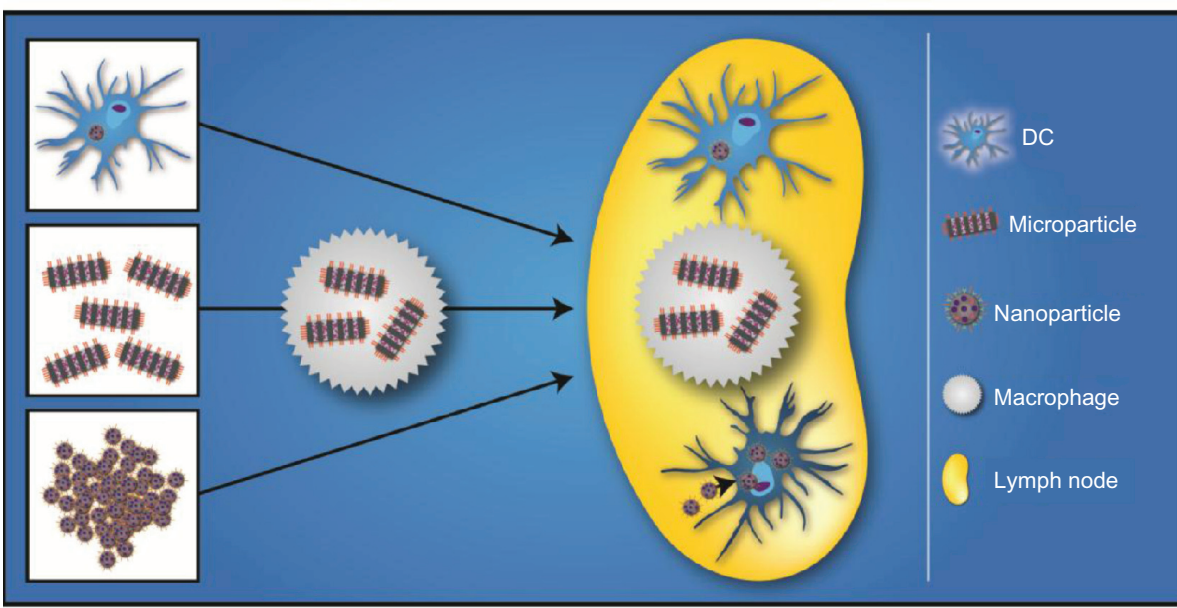

C

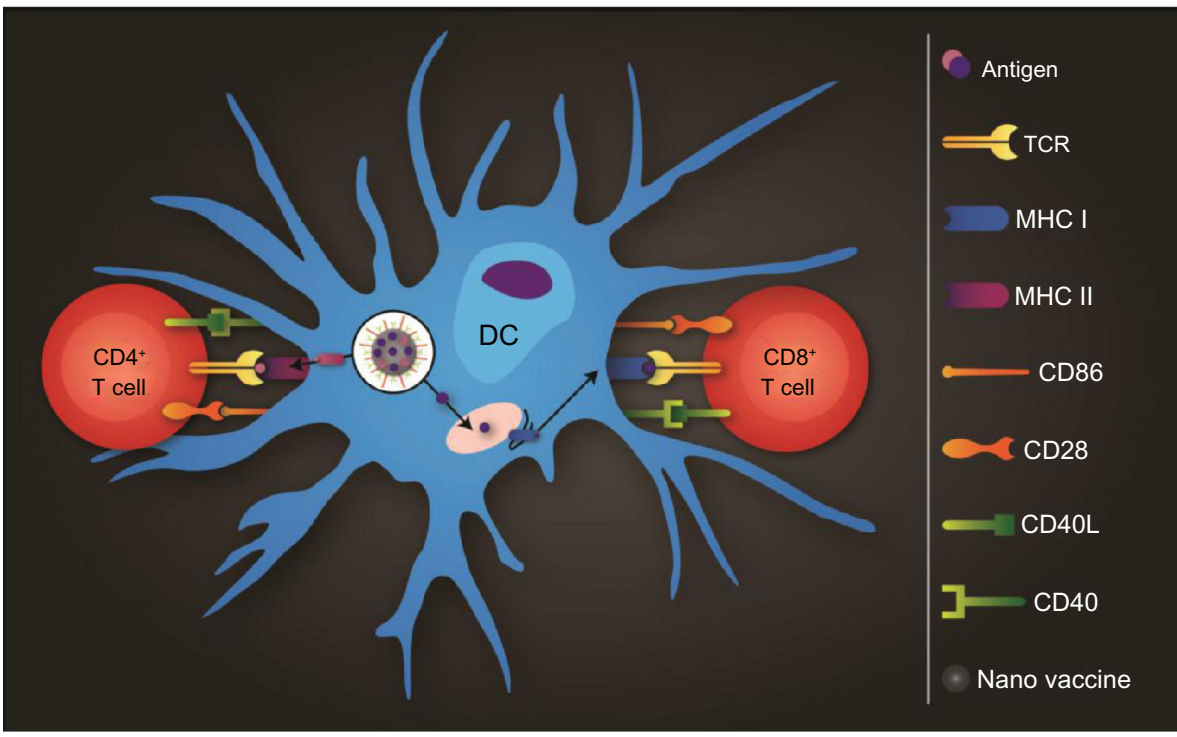

Figure I (A-C) Schematic overview of particle-based vaccines. (A) Three particle prototypes used to create therapeutic vaccines include porous silicon microparticles, poly(lactide-co-glycolide) nanoparticles, and liposomes. Each type of particle has unique features that impact its function and loading capacity, but potential common attributes include danger signals, antigens, immunomodulatory agents, and targeting entities. (B) Particle vaccines are either preloaded into dendritic cells (DCs) ex vivo or administered as free particles for in vivo uptake by antigen presenting cells (APCs). The size of the particle impacts its mode of transport to the lymph node, with large particles relying on cell-based trafficking and smaller nanoparticles independently entering the lymphatics. (C) DCs process and present antigens delivered by particles to T cells by means of the major histocompatibility complex (MHC) class I or II pathways.

Notes: Antigen processing and association with MHC II occurs within the endolysosomal pathway, while MHC I-dependent processing occurs within the proteasome and ER. Schematic by Matthew Landry.

Abbreviations: TCR, T-cell receptor; $C D$, cluster of differentiation.

Cell mediators of sustained immune responses are APCs, with DCs being recognized as potent activators of adaptive immunity. ${ }^{22}$ DCs engulf foreign objects by fluid-phase pinocytosis, receptor-mediated endocytosis, and phagocytosis, and secrete proinflammatory cytokines and chemokines.
Proteins are degraded into peptides and assembled with major histocompatibility complex (MHC) class I and II molecules. The classical path of MHC class II loading is exogenous antigen processing and loading within the endosomal pathway, while class I endogenous antigen processing 
occurs within the proteasome, with transporters associated with antigen-processing (TAP) transporting antigens into the endoplasmic reticulum for loading of MHC class I molecules (Figure 1C). ${ }^{23,24}$ In addition to proteasomal degradation, models proposed to explain MHC class I loading of exogenous protein (ie, cross-presentation) include a unique intercellular compartment known as an ergosome, which is a fusion compartment involving the phagosome and the ER. ${ }^{25,26}$ It has also been proposed that DCs have evolved to possess a unique endocytic trafficking pathway that facilitates recycled MHC I access to antigens within endosomal compartments. ${ }^{27}$

Successful engagement of a sustained anticancer immune response requires a complex set of interactions between activated $\mathrm{DC}$ and naive $\mathrm{T}$ and $\mathrm{B}$ cells. With respect to humoral immunity, DCs (1) induce naive B cells to differentiate into memory and plasma cells, (2) induce naive $\mathrm{CD} 4^{+} \mathrm{T}$ cells to differentiate into helper cells, (3) facilitate $\mathrm{CD} 4^{+} \mathrm{T}$-cell enhancement of B-cell immunoglobulin (Ig)-M production and favor isotype switching towards IgG, IgE, and IgA..$^{28,29}$ The second arm of adaptive immunity is cellular immunity. Under normal conditions, mature DCs are capable of activating T-lymphocyte populations endowed with high tumor-antigen avidity, including (1) effector $\mathrm{CD} 8^{+} \mathrm{T}$ cells, (2) memory $\mathrm{CD}^{+} \mathrm{T}$ cells, and (3) $\mathrm{CD}^{+} \mathrm{T}$-helper cells..$^{30,31}$ DCs present antigen to $\mathrm{CD} 4^{+} \mathrm{T}$ cells in association with MHC class II molecules and to $\mathrm{CD} 8^{+} \mathrm{CTLs}$ and effector $\mathrm{CD}^{+} \mathrm{T}$ cells in association with MHC class I molecules (Figure 1C). APCs present the antigen complex to naive $\mathrm{T}$ cells in association with costimulatory molecules, specifically CD80, CD86, and CD40, leading to activation of antigen-specific cytolytic functions and tumor eradication.

A key player in the development of humoral immunity is IL-12. Systemic delivery of IL-12 to patients with head and neck cancer leads to activation of B cells in draining lymph nodes, as well as tumor infiltration and regression. ${ }^{32}$ Existing paradigms state that IL-12 causes naive $\mathrm{T}$ cells to differentiate along the Th1 pathway. Conversely, antigen presentation in the absence of IL-12 or in the presence of immunosuppressive cytokines induces T-cell anergy and lack of antitumor immunity. However, IL-12 causes significant dose-dependent morbidity, requiring a mechanism or delivery vehicle to spatially or temporally limit IL-12 limit expression. Localized tumor delivery of IL-12 with liposomes has been demonstrated, ${ }^{33}$ and mechanisms for spatial and temporal gene expression include tissue-specific and stimuli-triggered promoters (eg, heat-shock promoters combined with heat-generating nanoparticles and laser light exposure). The use of ultrasound-sensitive liposomes containing perfluoropropane gas for IL-12 gene delivery has also been demonstrated. ${ }^{34}$ Other cytokine candidates for immunomodulation, such as IL-2, enhance the cytotoxicity of effector immune cells, but also cause significant dosedependent morbidity and act as positive regulators of $\mathrm{T}_{\text {reg }}$ cells. ${ }^{35}$ Cytokine candidates for effector cell activation also include IL-21, IL-18, and type I IFNs (IFN- $\alpha$ and $-\beta$ ). ${ }^{36}$ IL-18 has been given to patients with no dose-limiting toxicities. ${ }^{37}$ Stephan et $a l^{38}$ demonstrated that sustained pseudoautocrine stimulation of immune cells with IL-15, IL-15 receptor, and IL-21 elicited marked enhancement in tumor elimination in a model of adoptive T-cell therapy for cancer.

Encouraging clinical responses have been reported with combination therapy that includes inoculation with recombinant granulocyte macrophage colony-stimulating factor (GMCSF) and IFN- $\gamma \cdot{ }^{39}$ GM-CSF both stimulates differentiation of myeloid precursors towards the DC lineage and functions as a chemoattractant, luring DCs to either the tumor or the site of antigen deposition. Clinical use of GM-CSF has been shown to be safe and effective. ${ }^{40-42}$ GM-CSF gene therapy-based immunotherapy involves transducing cancer cells with vectors that express GM-CSF, such as GVAX therapy. ${ }^{43}$ The secreted GM-CSF both recruits DCs to the tumor site and stimulates DC antigen uptake and presentation. IFN- $\gamma$ is an immunostimulatory cytokine originally called "macrophage-activating factor." It is secreted by Th1 cells and increases lysosome activity, antigen presentation, and expression of MHC class I, as well as suppressing Th2 activity. IFN- $\gamma$ is active on both B and $\mathrm{T}$ cells, and has been demonstrated to inhibit the growth of preneoplastic and neoplastic mammary cells. ${ }^{44}$ Additionally, IFN- $\gamma$ antagonizes tumor growth by enhancing secretion of antiangiogenic chemokines. However, IFN- $\gamma$ alters transcription of a large array of genes, making localized therapy, such as nanoparticle-based delivery, attractive.

\section{Vaccine adjuvants}

Alum, the standard adjuvant used in the majority of immunization regimens, is a trivalent aluminum salt. It was first tested as an adjuvant in a tetanus toxin vaccine in 1926 by Glenny et al. ${ }^{45}$ Injection of alum causes macrophage and leukocyte migration to the injection site. Proposed mechanisms of action include entrapment/adsorption of antigens within mineral deposits for either sustained antigen release (depot effect) or enhanced antigen uptake by APCs. Alum is engulfed by macrophages, and is reported to persist inside the cell for several months. ${ }^{46,47}$ The depot effect of alum has been argued against based on continued adjuvant effects following excision of the injection site. ${ }^{48}$ Following uptake of alum by macrophages, it has controversially been suggested that alum 
induces lysosomal membrane rupture, leading to nucleotidebinding domain leucine-rich family pyrin-containing 3 gene activation. ${ }^{49}$ Also, while macrophages are able to internalize alum, it reportedly causes frustrated phagocytosis in DC, preventing uptake of the crystalline aggregates ${ }^{50}$ Interaction of alum with lipids in the plasma membrane of DC is thought to be accompanied by delivery of soluble antigen across the cell membrane, leading predominately to $\mathrm{Th} 2$-directed immune responses. However, it is reported that the presence of the TLR-4 ligand monophosphoryl lipid (MPL)-A can redirect alum-mediated immune responses towards Th1 $1{ }^{51,52}$ The use of MPL combined with aluminum (AS04) has been approved for clinical use in several viral vaccines. ${ }^{53}$

Cellular uptake of microbes is accompanied by engagement of pattern-recognition receptors, further contributing to cellular activation. Pattern-recognition receptors are specific for conserved microbial structures known as pathogenassociated molecular patterns (PAMPs), present on microbes or viruses. ${ }^{54,55}$ Activation of these receptors induces phagocytosis and expression of genes that cause maturation of the cell and activation of antimicrobial events, thereby inducing innate immunity. Particles carrying PAMPs similarly induce phagocytosis and elevate the activation of APCs. The scanning electron micrograph in Figure 2A shows a DC (blue), loaded with particles containing lipopolysaccharide (LPS) and antigen (ovalbumin [OVA]), being engaged by a $\mathrm{T}$ cell (red) expressing a transgenic TCR for recognition of the MHC I-presented antigen (image acquired using an FEI [Hillsboro, OR, USA] Nova NanoSEM by Victor Segura-Ibarra).
Formation of an immunological synapse between a DC and $\mathrm{T}$ cell is shown in the transmission electron micrograph in Figure 2B (image acquired using a JEOL [Tokyo, Japan] 1210 TE microscope by Jim Barrish with cell study by Brenda Melendez). The $\mathrm{T}$ cells in the images were isolated from the spleen of $\mathrm{C} 57 \mathrm{BL} / 6-\mathrm{Tg}(\mathrm{TcraTcrb})$ mice. The transgenic T-cell receptors recognize the OVA SIINFEKL peptide in association with MHC class I molecules. The DCs were treated with particles $(1 \mu \mathrm{m}$ discoidal porous silicon [pSi], 20 particles per cell dose) carrying the peptide and a TLR-4 ligand (LPS) prior to incubation with the T cells (3 hours), as previously published. ${ }^{56}$

\section{Particles as vaccine-delivery vehicles}

Recent advances in nanotherapeutics for cancer applications have provided diverse groups of synthetic particles with defined cellular and biological functions. Lipid and polymeric particles, as well as virus and virus-like particles, have been used to facilitate antigen delivery, with concurrent delivery of antigens and adjuvant serving to enhance what would otherwise be limited and short-lived responses to subunit vaccines. ${ }^{57}$ Benefits of particle-based carriers include long-term release of antigens, oriented antigen and/or adjuvant presentation, multivalent presentation, and targeting. The potential for encapsulated and sustained release of antigen within cells has been proposed to increase antigen-presentation time by $\mathrm{DCs},{ }^{58}$ permitting time for migration of DCs to lymphatic tissue within the presentation time window. This is in contrast to bare antigens, in which
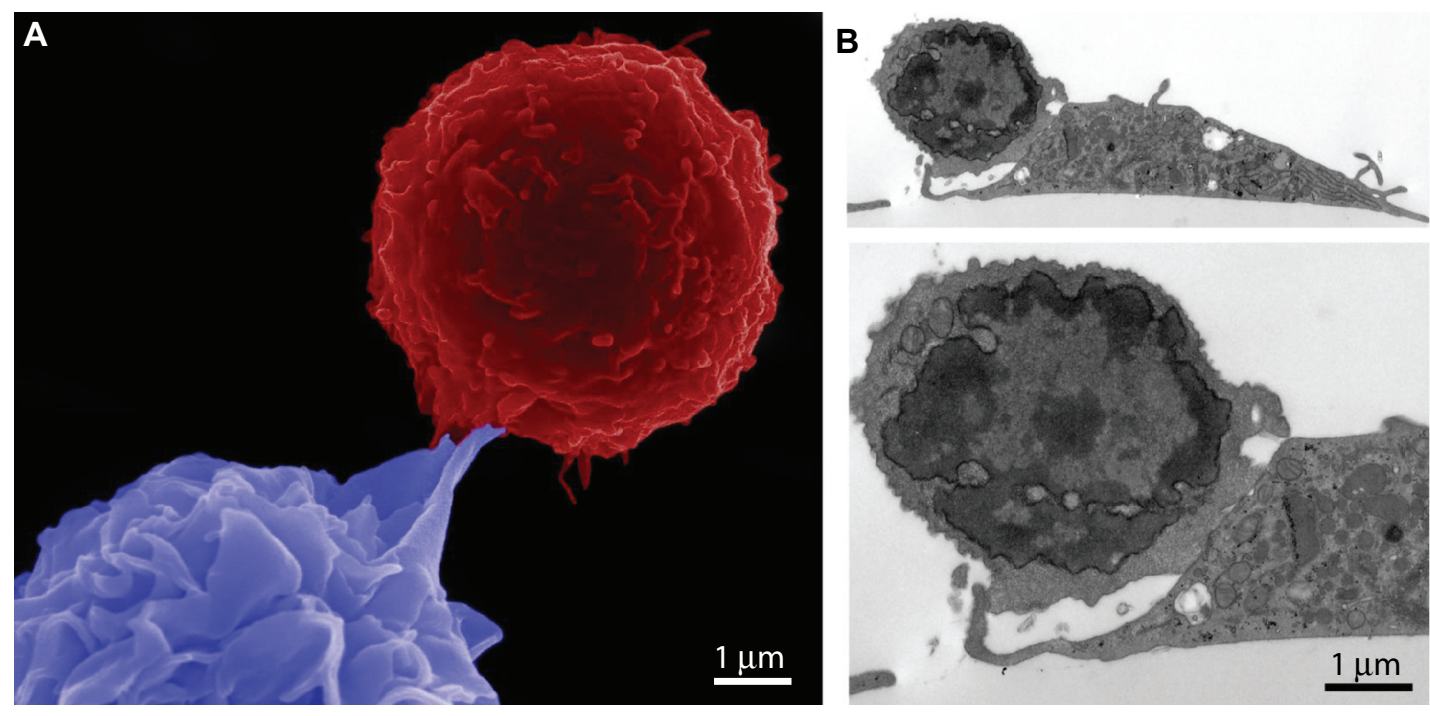

Figure 2 (A and B) Cellular interactions between dendritic cells (DCs) and T cells. DCs were generated from mouse C57BL/6 bone marrow cells and introduced to T cells isolated from C57BL/6-Tg(TcraTcrb) mice. The DCs were pretreated with silicon particles carrying the ovalbumin peptide and Toll-like receptor 4 ligand prior to incubation with the $\mathrm{T}$ cells. (A) Pseudocolored scanning electron micrograph showing a red $\mathrm{T}$ cell and a blue DC. (B) Transmission electron micrographs at 5000× and 10,000× magnification show adhesion between a T cell and DC. 
the presentation time is reportedly limited to 12 hours. It is hoped that sustained release of antigen from particles can induce strong protection, eliminating the need for repeated doses of the vaccine (prime-boost). ${ }^{59}$

Shen et $\mathrm{a}^{58}$ examined antigen uptake and $\mathrm{CD} 8^{+} \mathrm{T}$-cell activation in DCs treated with soluble antigen, or particles with surface-attached (latex or poly[lactide-co-glycolide] [PLGA] particles) or encapsulated antigen (PLGA particles). Antigen encapsulation resulted in increased cellular uptake of antigen and induced T-cell responses at 1000-fold lower antigen concentrations than free antigen, and tenfold lower concentrations than surface-attached antigen. While MHC class I presentation of particle-encapsulated antigen remained $80 \%$ effective at 96 hours postintroduction, there was no detectable presentation by cells treated with soluble or particle surface-coated antigens. The mechanism of antigen delivery was postulated to influence cross-presentation. Support for this mechanism is the finding that while macropinocytosis of soluble antigen leads to poor MHC class I presentation by APCs, phagocytosis of particle-packaged antigen enhances cross presentation, leading to potent CTL responses. ${ }^{60}$

With respect to the delivery of chemotherapeutic drugs, a major drawback of using synthetic carriers is entrapment of the particles within filtering organs, predominantly the liver and spleen. The major reason for particle accumulation within these organs is cellular uptake by phagocytic cells, predominately macrophages. While APC uptake of particles is a barrier to drug delivery, it facilitates immunotherapy, with particles thus offering a means for natural targeting of APCs and lymphatic tissue. In addition, while most vac- cines require the addition of adjuvants (ie, danger signals) to induce successful immune responses, ${ }^{61}$ some particulatebased vaccines are able to induce immune responses without additional adjuvants, ${ }^{62}$ making particles attractive agents for vaccine development.

Advances in particle engineering make it possible to create devices that mislead the host into recognizing particles as pathogens. ${ }^{63}$ Fabrication of particles in geometries resembling pathogens and the ability to orient pathogenrelevant danger signals on the particle surface activate APCs and stimulate particle uptake. Multivalent presentation of PAMPs or antigens by particles mimics repetitive presentation by live pathogens, ${ }^{63,64}$ leading to enhanced antigenicity through receptor cross-linking and immune-cell activation. Moon et a ${ }^{65}$ demonstrated that particle-based antigen presentation achieved a tenfold reduction in the amount of antigen needed to achieve equivalent antibody responses to that presented by conventional adjuvants. Enhanced diversity in antibody production was also observed with particlebased antigen presentation, potentially due to activation of lower-avidity B cells that would not be achieved with lower antigen densities. While high-valence antigen arrays successfully stimulated antibody generation by B cells, low-valence antigen arrays did not. ${ }^{66}$

An example of a rationally designed carrier is a $\mathrm{pSi}$ microparticle. ${ }^{67,68}$ For example, particles in the shape of rods resemble bacteria with respect to size and aspect ratio. The rod-shaped particles shown in Figure 3 were made by the nanofabrication team at the Methodist Hospital Research Institute, led by Dr Xuewu Liu. ${ }^{69}$ In Figure 3A, bacterial cells are pseudocolored in blue, rod-shaped $\mathrm{pSi}$ microparticles
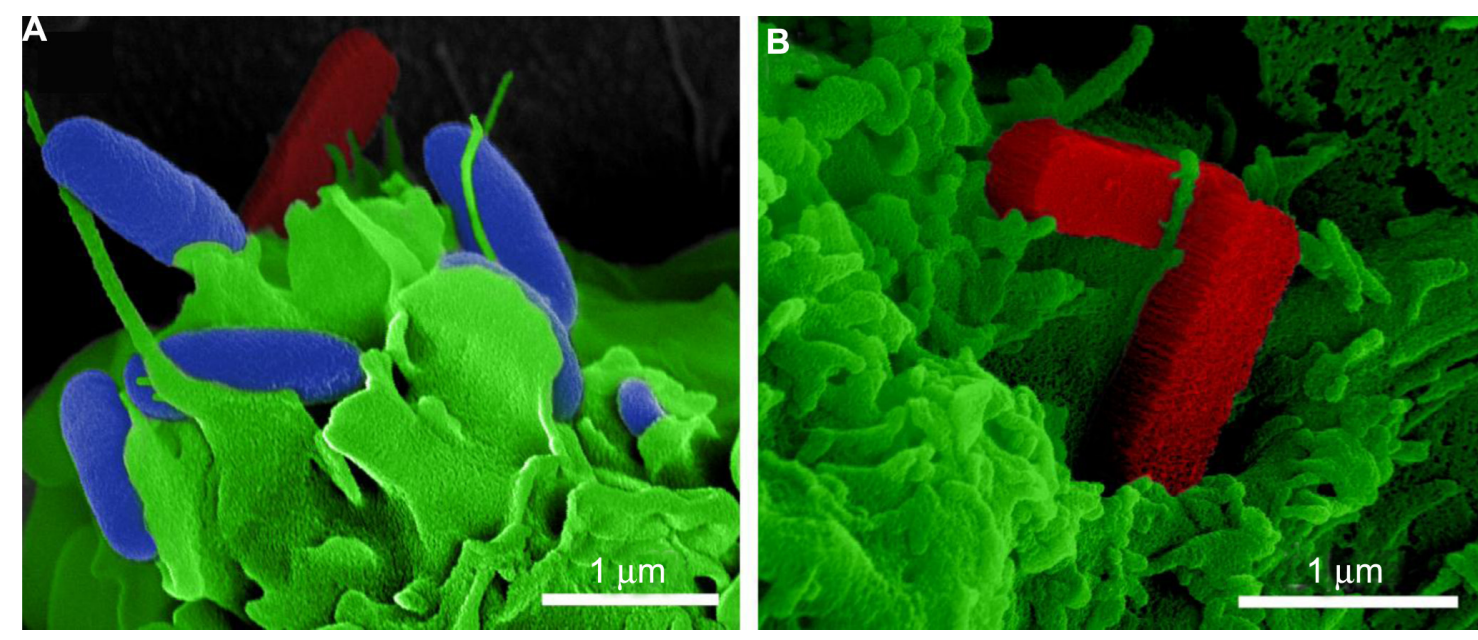

Figure 3 (A and B) Pathogen-mimicking silicon microparticles. Scanning electron micrographs show mouse bone marrow-derived dendritic cells, pseudocolored in green, with surface-bound bacteria (blue) and rod-shaped porous silicon microparticles (red). (A) Bacteria and silicon rods are shown together to emphasize size and shape similarities. (B) Silicon rods (red) are shown with cellular pseudopodia wrapped across one of the particles. 
in red, and the DC membrane in green. BALB/c-derived bone marrow-derived DCs (BMDCs) were incubated with a mixture of bacteria and silicon microparticles (ten particles per cell) for 30 minutes, then fixed, dehydrated, and sputtercoated with platinum-palladium (80:20) for imaging using an FEI Nova NanoSEM (images by Dr Jianhua Gu). Cellular uptake of the silicon particles was increased by addition of PAMPs (LPS) to the particle surface. Figure 3B shows two rod-shaped pSi microparticles $(1800 \times 400 \times 400 \mathrm{~nm})$ on the DC membrane, with cellular pseudopodia beginning to wrap around the particles. My research team previously demonstrated that both LPS and its lipid component MPL-A enhance DC uptake of pSi microparticles, increasing cellular activation and migration of DC to the draining lymph node. ${ }^{56}$ Particle presentation of antigen and TLR4 ligand also enhanced IFN- $\gamma$ production by $\mathrm{CD}^{+} \mathrm{T}$ cells. ${ }^{56}$ As a cautionary note, while the majority of studies show that TLR engagement leads to activation of innate and adaptive immune responses, enhancing the activity of cancer vaccines, some studies indicate that TLR4 agonists promote tumor-cell survival and growth in some cancer types. ${ }^{70}$

\section{Antigen uptake and presentation by APCs}

Obstacles encountered for DC-based vaccines include limited tumor regression based on lack of effective antigen uptake by DCs. Both macrophages and DCs are potent APCs capable of internalizing targets by endocytosis, pinocytosis, or phagocytosis. However, while both $\mathrm{CD}^{+}$and CD8 ${ }^{-}$DCs are highly efficient at capturing antigen (both free and particle-bound), only $\mathrm{CD}^{+} \mathrm{DCs}$ are highly efficient at presenting exogenous antigen in association with $\mathrm{MHC}$ class I molecules (ie, cross-presentation). ${ }^{71-73} \mathrm{CD} 8^{+} \mathrm{DCs}$ are the main APC population in vivo capable of internalizing dead cells and presenting antigen to $\mathrm{CD}^{+}$and $\mathrm{CD}^{+}$cells. Interestingly, TLR ligands impair cross-presentation of dead cell antigens in mature $\mathrm{CD} 8^{+} \mathrm{DC}$, but stimulate this action in newly derived (pre-CD8 ${ }^{+}$) DC when stimulated prior to antigen presentation. ${ }^{74}$

DC uptake of nanoparticles occurs at all stages of cellular maturation; however, with respect to microparticles $(2-3 \mu \mathrm{m}$ diameter), it is reported that only immature DCs are able to engulf microparticles..$^{23,75,76}$ In vivo, rapid uptake of larger particles by macrophages is reported to precede that of DCs. Also, antigen processing and cytokine responses are reported to differ for macrophages and DCs. For example, DCs are more efficient at cross-presentation than macrophages, increasing $\mathrm{MHC}$ class I presentation of antigens. In addition, activation of macrophages and DCs favors secretion of discrete cytokines, specifically TNF- $\alpha$ and IFN- $\gamma \cdot{ }^{77}$

Following cellular uptake, the large majority of nano- and microparticles traffic along the endolysosomal pathway. It has been demonstrated that antigen processing following particle uptake is inhibited by the presence of chloroquine, indicating that phagolysosomal enzymes are essential for antigen processing. ${ }^{78}$ Nano- and microparticles are reported to impact differentially the rate of endosomal degradation by favoring more (nano-) or less (micro-) acidic environments. ${ }^{79}$ Thus, particle size is an important determinant of cellular uptake, and it impacts both intracellular trafficking of particles and cargo, and antigen processing.

\section{Influence of particle physicochemical properties on cellular responses}

Size and aspect ratio of particles are important properties that impact particle biodistribution, cellular interactions, and cellular internalization. ${ }^{80-82}$ Using polystyrene particles, Foged et $\mathrm{al}^{76}$ reported that the optimal particle size for uptake by human blood-derived DCs was $0.5 \mu \mathrm{m}$, with uptake predominantly occurring for particles $0.5 \mu \mathrm{m}$ and smaller. DC uptake of polystyrene particles larger than $1 \mu \mathrm{m}$ was, however, enhanced by modifying the particles to have a cationic surface charge. Particles that were too large for phagocytosis induced frustrated phagocytosis, with prolonged frustration leading to a persistent inflammatory response, including an increase in reactive oxygen species (ROS).

Particle size also has an impact on the APC population that engulfs the particle, based largely on particle-transport physics. Particles have been shown to traffic to the draining lymph node in a size-dependent manner, as illustrated in Figure 1B. Large particles (500-2000 nm) are engulfed by peripheral APCs at the site of injection, while small nanoparticles (20-200 $\mathrm{nm}$ ) are internalized in DCs and macrophages residing in lymph nodes. ${ }^{83}$ Smaller nanoparticles were independently able to diffuse across the interstitium and enter the lymphatic system, while delayed transport of larger nanoparticles to lymph nodes supports a requirement for cell-based transport. ${ }^{83}$ Reddy et al demonstrated that lymphatic uptake of nanoparticles (poly[propylene sulfide]) was greater for $20 \mathrm{~nm}$ particles compared to 45 and $100 \mathrm{~nm}$ particles. ${ }^{84}$ Approximately half of lymph-node DCs contained intracellular $20 \mathrm{~nm}$ nanoparticles. In a separate study, carboxylated polystyrene nanoparticles of various sizes, normalized for equal doses of conjugated antigen, were used to study size-dependent immunogenicity. ${ }^{59}$ The optimal particle size for immune-cell stimulation was in the 
viral size range. Particles 40-50 $\mathrm{nm}$ in size elicited stronger T-cell responses compared to other particles ranging from 20 to $2000 \mathrm{~nm}$. Greater lymph-node accumulation was observed for the $40 \mathrm{~nm}$ particles, with particles present for greater than 14 days. Immune responses occurred in the absence of adjuvant, indicating that the particles themselves were stimulatory. Of special interest was the finding that $40 \mathrm{~nm}$ particles were housed within DEC $205^{+} / \mathrm{CD} 40^{+} \mathrm{DC}$, a mature/ activated DC subset, while $1000 \mathrm{~nm}$ particles were predominately located in F4/80 macrophage-like cells within the draining lymph node. Covalent conjugation of antigen (OVA, human papilloma virus peptide E7.1) to the nanoparticles supported antibody and CD $8^{+} \mathrm{T}$-cell immunity and provided protective immunity upon animal challenge with EL4 cells. IFN- $\gamma$ type I responses were greater for OVA presented on 40-50 nm particles compared to other sizes. In contrast, IL-4 Th2 responses were greatest when OVA was presented with particles $93-123 \mathrm{~nm}$ in diameter. ${ }^{85}$

With respect to PLGA-1-pyrenemethylamine (PMA): $\beta$ poly(lactic acid-poly(ethylene glycol) (PEG) PLGAPMA:PLA-PEG particles, lymph-node accumulation and retention was found to be greatest for $50 \mathrm{~nm}$ particles when compared with 100 and $200 \mathrm{~nm}$ particles. ${ }^{86}$ Both size and hydrophobicity were inversely related to lymph-node accumulation. Anionic PLGA particles (PLGA-PMA:PLGA$\mathrm{COOH})$ revealed a correlation between increasing negative charge density and faster rates of movement through the interstitium. Anionic PLGA particles with high charge density showed much greater accumulation within the lymph node than their PEGylated size equivalents.

Particle stability is a major determinant of drug-release rate. Both liposomes and polymers, such as the polylactides PLA and PLGA, are rapidly hydrolyzed in the body. When compared side-by-side at similar particle sizes, PLGA particles have slower antigen-release kinetics compared to liposomes. ${ }^{87}$ Ex vivo stimulated splenocytes from PLGA particle-vaccinated mice displayed higher IFN- $\gamma$ responses compared to splenocytes from liposome-vaccinated mice. The slower release kinetics from PLGA compared to liposomes was thought to account for more effective in vivo $\mathrm{CD} 8^{+} \mathrm{T}$-cell responses. An anticipated advantage of sustained release is single-inoculation therapy rather than treatment with prime and boost injections. The importance of understanding release and degradation kinetics, as well as metabolic products is also exemplified by the potential for particle-degradation to influence the immune response. As an example, hydrolyzed acidic metabolites (glycolic, lactic, silicic) have the potential to alter $\mathrm{pH}$ and cause inflammation. ${ }^{88}$
The inherent adjuvanticity of diverse classes of nanoparticles is exemplified by cationic liposomes. Inclusion of the cationic lipid 1,2-dioleoyl-3-trimethylammonium-propane (DOTAP) within nanoparticles leads to activation of mouse BMDCs. Yan and colleagues ${ }^{89}$ demonstrated that DOTAP, in a concentration-dependent manner, generated ROS in BMDCs, leading to ERK and p38 activation, cytokine/ chemokine production, and expression of the $\mathrm{B} 7$ costimulatory molecules CD80 and CD86. However, elevated levels of DOTAP also led to cellular labeling with annexin $\mathrm{V}$ and subsequent cell death. Within 2 hours, $8 \%, 68 \%$, and $91 \%$ of cells treated with 50, 200, and $800 \mu \mathrm{M}$ DOTAP were doublepositive for annexin $\mathrm{V}$ and ROS. The optimal in vivo dose in mice for ROS production in the draining lymph node and antiTC-1 tumor activity was 100 nmol DOTAP in the cationic liposome/E7 peptide formulation.

\section{Influence of particles on the inflammasome}

Inflammasomes are multiprotein complexes that function to activate caspase-1, leading to the proteolytic maturation of proinflammatory cytokines. ${ }^{90,91}$ Early signals stimulate expression of precursor cytokines, such as pro-IL-1 $\beta$, while secondary signals activate the inflammasome, liberating active cytokines. Activation of the inflammasome is thought to be a multistep process, with particulates having the ability to prime cells for subsequent LPS-induced secretion of IL-1 $\beta$ from DCs. ${ }^{92}$ Phagocytosis of particulates, such as PLG and polystyrene, enhanced LPS induced secretion of IL- $1 \beta$ from DCs. ${ }^{92}$ Sharp et al ${ }^{92}$ tested four particle sizes and found that 0.43 and $1 \mu \mathrm{m}$ particles were taken up by DCs, while larger particles, 10 and $32 \mu \mathrm{m}$, had limited uptake. Both the 0.43 and $1 \mu \mathrm{m}$ particles were potent inducers of IL- $1 \beta$ secretion, while the larger particles were mildly stimulatory. Blockade of phagocytosis with cytochalasin B or D significantly reduced particulate enhanced IL-1 $\beta$ secretion.

\section{Complement opsonization of particles}

The immunogenicity of carbon nanotubes (CNTs) is reported to vary with structure and surface characteristics. For example, functionalized CNTs are more stimulatory than their nonfunctionalized counterparts. ${ }^{93}$ Following contact with blood, CNTs and other types of nanoparticles may trigger the complement system. For example, pristine CNTs are bound directly by $\mathrm{C} 1 \mathrm{q}$, leading to complement activation. ${ }^{94}$ Just as complement fragments prime the surface of microbes, they opsonize particles for recognition and clear- 
ance by phagocytic cells. Optimization of particle-surface properties to drive opsonization is a potential mechanism for APC targeting.

\section{Targeted nanoparticles}

Targeting of specific cell populations with particles has been described as passive or active. ${ }^{82,95}$ Passive targeting is influenced by intrinsic particle properties, including size, charge, and rigidity. Physiological factors influencing particle trafficking and tissue-specific accumulation include lymphatic and hemodynamic forces, diffusive mechanisms, and epithelial/endothelial permeability. ${ }^{96}$ Active targeting involves the addition of ligands or surface coating to the particle exterior to direct cellular interactions (Figure 1A).

As stated previously, the presence of microbial surface antigens on particles can facilitate cellular uptake by DCs through recognition and activation of surface receptors. Examples include C-type lectin receptors (CLRs) for sugar moieties (eg, mannose) and TLR for PAMPs. Engagement of both CLRs and TLRs can lead to receptor-mediated endocytosis. ${ }^{56,97}$ Receptor binding (CLRs, TLRs, and cytokine) may also induce DC maturation, achieving both uptake and immune-cell activation. Other receptor targets include integrins, CD40, and CD11c, which have been targeted using specific antibodies. ${ }^{98}$ Cellular DC lectin targets include CD205 (DEC205), mannose receptor, DC-SIGN (SIGNR mouse homologues) and CD1a. ${ }^{99}$

The impact of ligand-receptor interactions on cellular function should also be taken into consideration. For example, targeting TLR with ligands results in DC maturation, and has been shown to favor Th1 responses. LPS, pathogen-derived lipopeptides, and flagellin all interact with cell-surface TLRs. The TLR engagement causes the production of type 1 IFN and proinflammatory cytokines, as well as enhanced surface expression of costimulatory molecules. Clinical studies using TLR agonists have demonstrated some success in basal cell carcinoma patients treated with imiquimod. ${ }^{100}$ Other ligands, including CCR2, recruit DC precursors (Ly6 $\mathrm{C}^{\text {high }}$ cells) to inflammatory sites and favor DC differentiation. ${ }^{101}$ TLR2 ligation, on the other hand, favors induction of $\mathrm{T}_{\text {reg }}$ cells and should be avoided. ${ }^{102} \mathrm{DC}$ SIGN engagement activates a Raf-1-dependent pathway that alters nuclear factor kappa- $\beta$ activation. ${ }^{103}$ Surface engagement of specific lectins, including dectin-1, lectin-type oxidized low-density lipoprotein receptor 1, and DC-SIGN initiate intracellular signaling, leading to DC activation. ${ }^{104}$ In short, it is critical to match molecular targets with desired immune outcomes.

\section{DNA and viral vaccine components}

DNA has inherent traits that contribute to immunogenicity, such as $\mathrm{CpG}$ motifs and its double-stranded structure. $\mathrm{CpG}$ motifs are comprised of unmethylated $\mathrm{C}$ followed by $\mathrm{G}$ and certain flanking regions. Despite $\mathrm{CpG}$ motif recognition by TLR9, its immunogenicity in human trials has been low. TLR9 is located in the endoplasmic reticulum in resting DCs and macrophages. It translocates to the endosome when cells are stimulated with CpG DNA. ${ }^{105}$ Thus, endocytosis of CpG-bound particles is likely to enhance antigen immunogenicity through sustained TLR9 stimulation. Conversely, the structure of double-stranded DNA stimulates a proinflammatory type I IFN response, independent of TLRs. ${ }^{106,107}$ The delivery of therapeutic DNA is advantageous for cancer vaccines because it causes endogenous protein expression and processing along the proteasomal Th1 pathway.

Genetically modified plant and animal viruses, bacteriophages, and Archaea viruses are being explored as nanotechnology gene-delivery vehicles. ${ }^{108}$ The genetically engineered virus-vector vaccines express antigenic proteins, and potential expression of epitopes within the surface capsid provides multivalent presentation of antigens, adjuvant, and/ or targeting ligands. For example, cowpea mosaic virus is an example of a plant pathogen that has been used successfully to induce neutralizing antibodies against infectious agents in animals. ${ }^{109}$ Unfortunately, despite successful safety and efficacy testing in animals, some human trials have resulted in unwanted side effects and species-dependent differences in biological responses.

Oncogenic viruses induce malignant transformation in epithelial cells by inserting active oncogenes into the host genome. These viruses include human papilloma, ${ }^{110}$ hepatitis B, ${ }^{111}$ and Epstein-Barr ${ }^{12}$ viruses. The role of the hepatitis virus in the etiology of hepatocellular carcinoma is under investigation, and the role of the Epstein-Barr virus in the etiology of cervical cancer has led to the US FDA approving vaccines to protect against Epstein-Barr virus infection. Despite the negative role of viral agents in cancer, there is support for the use of nonpathogenic viruses as gene-delivery agents for cancer therapeutics. An example of a regulatory approved (Philippines), nanosized, anticancer agent is Rexin-G. ${ }^{113}$ Rexin-G is a replication-incompetent retroviral vector encoding an $\mathrm{N}$-terminal deletion mutant of cyclin $\mathrm{G}_{1}$. The vector specifically targets tumor tissue based on recognition of collagenous proteins associated with angiogenesis and collagen-matrix exposure due to insertion of a collagen-binding motif in the vector's envelope protein. Phase $\mathrm{I} / \mathrm{II}$ clinical studies in pancreatic cancer show that Rexin-G 
administration is associated with significant tumor regression and prolonged progression-free survival. ${ }^{114}$

A human parvovirus, the adenoassociated virus (AAV), is non-pathogenic, lacks toxicity, and can sustain longterm gene expression. ${ }^{115}$ AAV are currently in clinical trials for Parkinson's disease, muscular dystrophy, ocular diseases and hemophilia B. Recombinant AAV vectors are void of all virus-encoded genes, resulting in low intrinsic immunogenicity. Various AAV serotypes exist, and they differ with respect to cellular uptake by various cell populations. The ability to modify surface-exposed amino acids on their capsid can be used to enhance cellular targeting. Thus, multiple viral options, with tunable cargo and surface attributes, exist for gene delivery. Synthetic particles may be beneficial for encapsulating viral nanoparticles, reducing potential host reactions.

\section{Peptide and protein cargo}

Ex vivo loading of DCs with antigen has been used to create vaccines with limited success. ${ }^{116}$ Examples of immunotherapy include therapeutic vaccination with synthetic peptides, proteins, cell lysates, RNA, and necrotic or apoptotic tumor cells. ${ }^{117} \mathrm{~T}$ cells derived from vaccination with synthetic or modified peptides have thus far resulted in $\mathrm{T}$ cells with poor cytolytic function, however the delivery of protein involving endogenous antigen processing and epitope selection results in superior antigen presentation and improved immune responses. Unfortunately, a large number of immunotherapeutic approaches use single antigens or peptides to elicit antigen-specific immune responses. This is counterproductive based both on immunodominance (loss of target-antigen expression by cancer cells) and the finding that endogenous processing and presentation of antigen for presentation is far more efficient than presentation of free peptides. Apoptotic cell presentation of whole proteins was shown to be 10,000-50,000 times more efficient than that with free peptide. ${ }^{118}$

An example of a protein-based vaccine is FDA approved (2010) Provenge, by Dendreon Corporation (Seattle, WA, USA). Provenge is an autologous vaccine in which the patient's peripheral blood mononuclear cells are incubated ex vivo with a recombinant fusion protein expressing prostatic acid phosphatase and GM-CSF. ${ }^{119}$ The treated cells are either infused into the patient alone or in combination with chemotherapeutics. In clinical trials, all patients developed immune responses to the recombinant-fusion protein, and $38 \%$ developed response to prostatic acid phosphatase. ${ }^{119}$
The first clinical trial of Provenge (sipuleucel-T) resulted in a 4.5-month increase in overall survival at the 36-month follow-up. ${ }^{120}$ Currently, a phase II clinical trial is ongoing in which prostate cancer patients are treated with cyclophosphamide or CT-011 (anti-PD-1) in combination with three cycles of the vaccine.

\section{Hybrid-particle constructs}

Advantages of using microparticles for immunotherapy include rapid phagocytosis by immune cells and the ability to create hybrid platforms that achieve diverse functions. An example is a pSi microparticle capable of carrying a payload of secondary nanoparticles or a complex cargo of antigens, immune modulators (eg, cytokines, small interfering RNA), and danger signals (Figure 1A) ${ }^{56,121}$ pSi microparticles can carry a payload of diverse or same-type nanoparticles, with each formulation loaded with a distinct therapeutic cargo. The microparticles are rapidly internalized by both macrophages and DCs. ${ }^{56,121,122}$ A hybrid-particle platform comprised of iron oxide nanoparticles loaded within a discoidal pSi microparticle is shown in the scanning electron microscope image in Figure 4A. ${ }^{121,123}$ The nanoparticles are loaded into the microparticle by capillary action, with retention by electrostatic interactions. The nanoparticle-loaded pores are shown at higher magnifications in Figure 4B and C. We recently demonstrated that this platform has the potential for dual-site intracellular targeting, with particles reaching both the endosome and the cytosol. ${ }^{123}$ We also demonstrated that labeling of the pSi microparticle with danger signals (LPS and MPL) enhances migration of carrier DCs to the lymph node and stimulates expression of costimulatory molecules and cytokines. Hybrid vectors may thus be advantageous over single particle constructs, based on (1) codelivered combination therapy, (2) shielded delivery of secondary nanoparticles, and (3) the potential for dual-site intracellular targeting and subsequent antigen processing by both the MHC class I and II pathways.

\section{Conclusions}

Benefits of using particles for immunotherapy include uptake by APC, targeting, shielded trafficking of cargo, codelivery of immunomodulatory agents and antigen, and sustained release of antigen eliminating the need for repeated doses of the vaccine. The tunability of particles makes it possible to make particles in discrete sizes and geometries. Surface functionalization makes it possible to orient pathogen-relevant danger signals on the particle surface and enables multivalent 

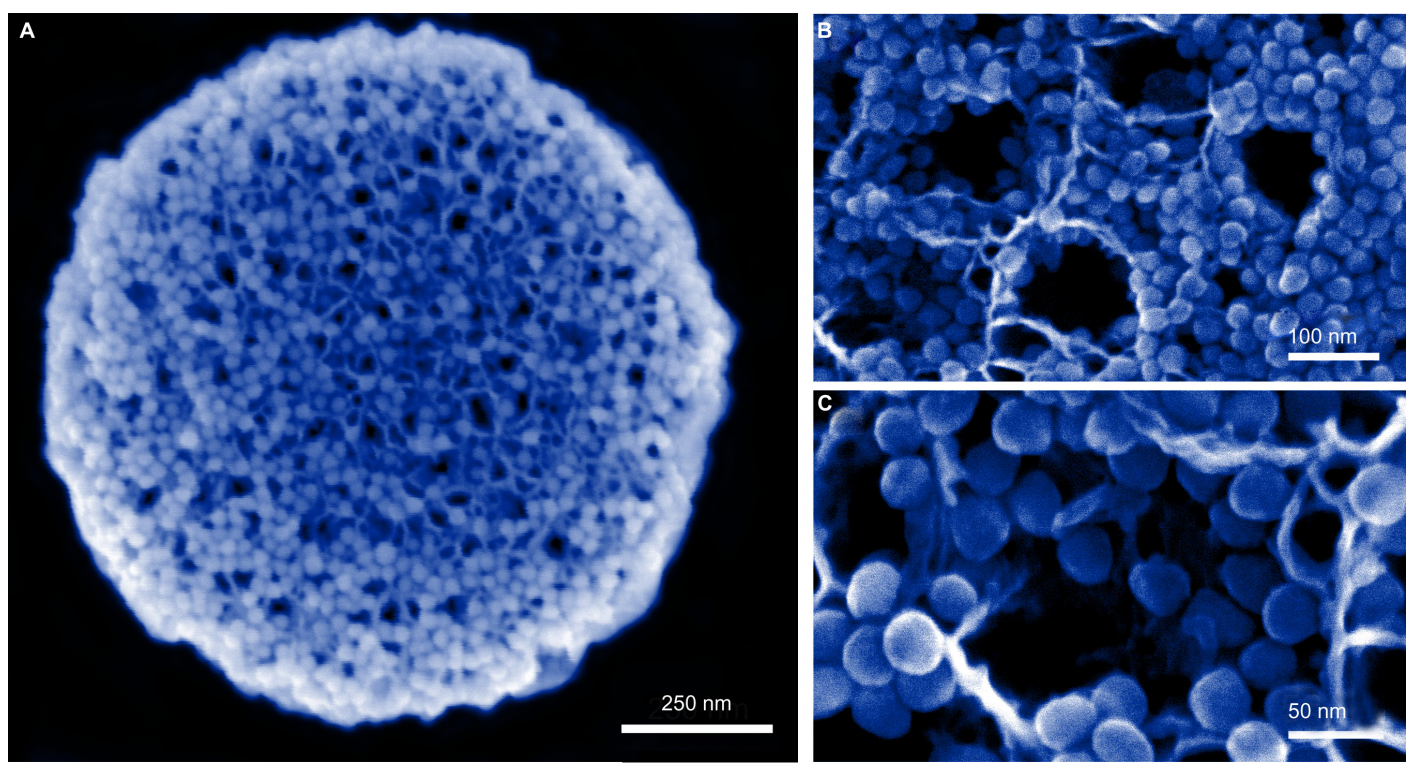

Figure 4 (A-C) Hybrid particle platforms as therapeutic delivery vehicles. Discoidal porous silicon microparticles are shown in scanning electron micrographs loaded with $30 \mathrm{~nm}$ iron oxide nanoparticles (IONPs). (A) Image captured using a FEI Nova NanoSEM using $100 \mathrm{kx}$ magnification. (B and C) Images captured at $200 \mathrm{kx}$ (B) and $450 \mathrm{kx}$ (C) magnification using a Hitachi S-5500 scanning electron microscope.

Reprinted from Small, Volume 6, Serda et al, Cellular Association and Assembly of a Multistage Delivery System, pages I329-1340. Copyright (C 20I0, with permission from John Wiley and Sons. ${ }^{121}$

presentation of PAMPs or antigens, mimicking repetitive presentation by live pathogens and leading to enhanced antigenicity through receptor cross-linking and immune-cell activation. The development of hybrid-particle platforms may be advantageous over single-particle constructs based on codelivery of multiple therapeutic agents to the same target cell, shielded delivery of secondary nanoparticles, and the potential for dualsite intracellular targeting and subsequent antigen processing by both the MHC class I and II pathways.

\section{Acknowledgments}

I wish to thank current and former members of my laboratory, including Dr Jianhua Gu, Brenda Melendez, and Victor Segura-Ibarra, for cellular studies and images presented in Figures 2 and 3. Special thanks to James P Barrish, technical specialist in the Department of Pathology Electron Microscopy Facility at Texas Children's Hospital for transmission electron microscopy $\times$ sample preparation and imaging. I acknowledge use of the Methodist Hospital Research Institute (TMHRI) scanning electron microscopy core, directed by Dr Rita Serda and equipped with an FEI Nova NanoSEM 230, and the TMHRI nanofabrication core, directed by Dr Xuewu Liu, for silicon-particle fabrication. Special thanks to Mr Matthew Landry, graphical artist at TMHRI, for graphically preparing the schematic displayed in Figure 1.

\section{Disclosure}

The author reports no conflicts of interest in this work.

\section{References}

1. Swann JB, Smyth MJ. Immune surveillance of tumors. J Clin Invest. 2007;117(5):1137-1146.

2. Dunn GP, Bruce AT, Ikeda H, Old LJ, Schreiber RD. Cancer immunoediting: from immunosurveillance to tumor escape. Nat Immunol. 2002;3(11):991-998.

3. Balkwill F, Mantovani A. Inflammation and cancer: back to Virchow? Lancet. 2001;357(9255):539-545.

4. Virchow RLK. Cellular Pathology as Based upon Physiological and Pathological Histology. Philadelphia: JB Lippincott; 1863.

5. Keibel A, Singh V, Sharma MC. Inflammation, microenvironment, and the immune system in cancer progression. Curr Pharm Des. 2009;15(17): 1949-1955.

6. Lin EY, Pollard JW. Tumor-associated macrophages press the angiogenic switch in breast cancer. Cancer Res. 2007;67(11):5064-5066.

7. Karlmark KR, Weiskirchen R, Zimmermann HW, et al. Hepatic recruitment of the inflammatory Gr1+ monocyte subset upon liver injury promotes hepatic fibrosis. Hepatology. 2009;50(1):261-274.

8. Markiewski MM, Lambris JD. Is complement good or bad for cancer patients? A new perspective on an old dilemma. Trends Immunol. 2009;30(6):286-292.

9. Markiewski MM, Lambris JD. The role of complement in inflammatory diseases from behind the scenes into the spotlight. Am J Pathol. 2007; 171(3):715-727.

10. Ricklin D, Lambris JD. Complement-targeted therapeutics. Nat Biotechnol. 2007;25(11):1265-1275.

11. Markiewski MM, DeAngelis RA, Benencia F, et al. Modulation of the antitumor immune response by complement. Nat Immunol. 2008;9(11): $1225-1235$.

12. Galluzzi L, Senovilla L, Zitvogel L, Kroemer G. The secret ally: immunostimulation by anticancer drugs. Nat Rev Drug Discov. 2012; 11(3):215-233. 
13. Ghiringhelli F, Apetoh L, Tesniere A, et al. Activation of the NLRP3 inflammasome in dendritic cells induces IL-1beta-dependent adaptive immunity against tumors. Nat Med. 2009;15(10):1170-1178.

14. Apetoh L, Ghiringhelli F, Tesniere A, et al. Toll-like receptor 4-dependent contribution of the immune system to anticancer chemotherapy and radiotherapy. Nat Med. 2007;13(9):1050-1059.

15. Demaria S, Volm MD, Shapiro RL, et al. Development of tumorinfiltrating lymphocytes in breast cancer after neoadjuvant paclitaxel chemotherapy. Clin Cancer Res. 2001;7(10):3025-3030.

16. Tsavaris N, Kosmas C, Vadiaka M, Kanelopoulos P, Boulamatsis D. Immune changes in patients with advanced breast cancer undergoing chemotherapy with taxanes. Br J Cancer. 2002;87(1):21-27.

17. Zitvogel L, Kepp O, Kroemer G. Immune parameters affecting the efficacy of chemotherapeutic regimens. Nat Rev Clin Oncol. 2011;8(3): 151-160.

18. DeNardo DG, Brennan DJ, Rexhepaj E, et al. Leukocyte complexity predicts breast cancer survival and functionally regulates response to chemotherapy. Cancer Discov. 2011;1(1):54-67.

19. Denkert C, Loibl S, Noske A, et al. Tumor-associated lymphocytes as an independent predictor of response to neoadjuvant chemotherapy in breast cancer. J Clin Oncol. 2010;28(1):105-113.

20. Kang TH, Mao CP, Lee SY, et al. Chemotherapy acts as an adjuvant to convert the tumor microenvironment into a highly permissive state for vaccination-induced antitumor immunity. Cancer Res. Epub February 15, 2013.

21. Munn DH, Cheung NK. Antibody-dependent antitumor cytotoxicity by human monocytes cultured with recombinant macrophage colonystimulating factor. Induction of efficient antibody-mediated antitumor cytotoxicity not detected by isotope release assays. $J$ Exp Med. 1989; 170(2):511-526.

22. Banchereau J, Briere F, Caux C, et al. Immunobiology of dendritic cells. Annu Rev Immunol. 2000;18:767-811.

23. Joshi MD, Unger WJ, Storm G, van Kooyk Y, Mastrobattista E. Targeting tumor antigens to dendritic cells using particulate carriers. J Control Release. 2012;161(1):25-37.

24. Burgdorf S, Kautz A, Bohnert V, Knolle PA, Kurts C. Distinct pathways of antigen uptake and intracellular routing in CD4 and CD8 T cell activation. Science. 2007;316(5824):612-616.

25. Guermonprez P, Saveanu L, Kleijmeer M, Davoust J, Van Endert P, Amigorena S. ER-phagosome fusion defines an MHC class I crosspresentation compartment in dendritic cells. Nature. 2003;425(6956): $397-402$.

26. Houde M, Bertholet S, Gagnon E, et al. Phagosomes are competent organelles for antigen cross-presentation. Nature. 2003;425(6956): 402-406.

27. Basha G, Lizee G, Reinicke AT, Seipp RP, Omilusik KD, Jefferies WA. MHC class I endosomal and lysosomal trafficking coincides with exogenous antigen loading in dendritic cells. PLoS One. 2008;3(9):e3247.

28. Avery DT, Bryant VL, Ma CS, de Waal Malefyt R, Tangye SG. IL-21induced isotype switching to $\operatorname{IgG}$ and $\operatorname{IgA}$ by human naive B cells is differentially regulated by IL-4. J Immunol. 2008;181(3):1767-1779.

29. Banchereau J, Rousset F. Human B lymphocytes: phenotype, proliferation, and differentiation. Adv Immunol. 1992;52:125-262.

30. Veiga-Fernandes H, Walter U, Bourgeois C, McLean A, Rocha B. Response of naive and memory CD8+ T cells to antigen stimulation in vivo. Nat Immunol. 2000;1(1):47-53.

31. Kaech SM, Ahmed R. Memory CD8+ T cell differentiation: initial antigen encounter triggers a developmental program in naive cells. Nat Immunol. 2001;2(5):415-422.

32. van Herpen CM, van der Voort R, van der Laak JA, et al. Intratumoral rhIL-12 administration in head and neck squamous cell carcinoma patients induces B cell activation. Int $J$ Cancer. 2008;123(10): 2354-2361.

33. Simpson-Abelson MR, Purohit VS, Pang WM, et al. IL-12 delivered intratumorally by multilamellar liposomes reactivates memory $\mathrm{T}$ cells in human tumor microenvironments. Clin Immunol. 2009;132(1): $71-82$.
34. Suzuki R, Oda Y, Utoguchi N, Maruyama K. Development of ultrasonic cancer therapy using ultrasound sensitive liposome. Yakugaku Zasshi. 2010;130(12):1665-1670. Japanese.

35. Wei S, Kryczek I, Edwards RP, et al. Interleukin-2 administration alters the CD4+FOXP3+ T-cell pool and tumor trafficking in patients with ovarian carcinoma. Cancer Res. 2007;67(15):7487-7494.

36. Huang X, Yu HS, Chen Z, Li JL, Hu ZM, Gao JM. A novel immunotherapy for superficial bladder cancer by the immobilization of streptavidin-tagged bioactive IL-2 on the biotinylated mucosal surface of the bladder wall. Chin J Cancer. 2010;29(6):611-616.

37. Robertson MJ, Kirkwood JM, Logan TF, et al. A dose-escalation study of recombinant human interleukin-18 using two different schedules of administration in patients with cancer. Clin Cancer Res. 2008;14(11): 3462-3469.

38. Stephan MT, Moon JJ, Um SH, Bershteyn A, Irvine DJ. Therapeutic cell engineering with surface-conjugated synthetic nanoparticles. Nat Med. 2010;16(9):1035-1041.

39. Schmeler KM, Vadhan-Raj S, Ramirez PT, et al. A phase II study of GM-CSF and rIFN-gammalb plus carboplatin for the treatment of recurrent, platinum-sensitive ovarian, fallopian tube and primary peritoneal cancer. Gynecol Oncol. 2009;113(2):210-215.

40. Simons JW. Bioactivity of human GM-CSF gene therapy in metastatic renal cell carcinoma and prostate cancer. Hinyokika Kiyo. 1997;43(11): 821-822.

41. Simons JW, Jaffee EM, Weber CE, et al. Bioactivity of autologous irradiated renal cell carcinoma vaccines generated by ex vivo granulocytemacrophage colony-stimulating factor gene transfer. Cancer Res. 1997;57(8):1537-1546.

42. Soiffer R, Lynch T, Mihm M, et al. Vaccination with irradiated autologous melanoma cells engineered to secrete human granulocytemacrophage colony-stimulating factor generates potent antitumor immunity in patients with metastatic melanoma. Proc Natl Acad Sci US A. 1998;95(22):13141-13146.

43. Dranoff G, Jaffee E, Lazenby A, et al. Vaccination with irradiated tumor cells engineered to secrete murine granulocyte-macrophage colonystimulating factor stimulates potent, specific, and long-lasting antitumor immunity. Proc Natl Acad Sci U SA. 1993;90(8):3539-3543.

44. Nanni P, Landuzzi L, Nicoletti G, et al. Immunoprevention of mammary carcinoma in HER-2/neu transgenic mice is IFN-gamma and B cell dependent. J Immunol. 2004;173(4):2288-2296.

45. Glenny AT, Pope CG, Waddington H, Wallace V. The antigenic value of toxoid precipitated by potassium alum. receptors control activation of adaptive immune responses. J Pathol Bacteriol. 1926;29: $38-45$.

46. Gherardi RK, Coquet M, Cherin P, et al. Macrophagic myofasciitis lesions assess long-term persistence of vaccine-derived aluminium hydroxide in muscle. Brain. 2001;124(Pt 9):1821-1831.

47. Verdier F, Burnett R, Michelet-Habchi C, Moretto P, Fievet-Groyne F, Sauzeat E. Aluminium assay and evaluation of the local reaction at several time points after intramuscular administration of aluminium containing vaccines in the Cynomolgus monkey. Vaccine. 2005;23(11): 1359-1367.

48. Marrack P, McKee AS, Munks MW. Towards an understanding of the adjuvant action of aluminium. Nat Rev Immunol. 2009;9(4):287-293.

49. Hornung V, Bauernfeind F, Halle A, et al. Silica crystals and aluminum salts activate the NALP3 inflammasome through phagosomal destabilization. Nat Immunol. 2008;9(8):847-856.

50. Flach TL, Ng G, Hari A, et al. Alum interaction with dendritic cell membrane lipids is essential for its adjuvanticity. Nat Med. 2011;17(4): 479-487.

51. Geurtsen J, Banus HA, Gremmer ER, et al. Lipopolysaccharide analogs improve efficacy of acellular pertussis vaccine and reduce type I hypersensitivity in mice. Clin Vaccine Immunol. 2007;14(7): 821-829.

52. Puggioni F, Durham SR, Francis JN. Monophosphoryl lipid A (MPL) promotes allergen-induced immune deviation in favour of Th1 responses. Allergy. 2005;60(5):678-684. 
53. Boland G, Beran J, Lievens M, et al. Safety and immunogenicity profile of an experimental hepatitis B vaccine adjuvanted with AS04. Vaccine. 2004;23(3):316-320.

54. Petrilli V, Dostert C, Muruve DA, Tschopp J. The inflammasome: a danger sensing complex triggering innate immunity. Curr Opin Immunol. 2007;19(6):615-622.

55. Akira S, Takeda K, Kaisho T. Toll-like receptors: critical proteins linking innate and acquired immunity. Nat Immunol. 2001;2(8): 675-680.

56. Meraz IM, Melendez B, Gu J, et al. Activation of the inflammasome and enhanced migration of microparticle-stimulated dendritic cells to the draining lymph node. Mol Pharm. Epub June 8, 2012.

57. Coffman RL, Sher A, Seder RA. Vaccine adjuvants: putting innate immunity to work. Immunity. 2010;33(4):492-503.

58. Shen H, Ackerman AL, Cody V, et al. Enhanced and prolonged cross-presentation following endosomal escape of exogenous antigens encapsulated in biodegradable nanoparticles. Immunology. 2006;117(1): $78-88$.

59. Fifis T, Gamvrellis A, Crimeen-Irwin B, et al. Size-dependent immunogenicity: therapeutic and protective properties of nano-vaccines against tumors. J Immunol. 2004;173(5):3148-3154.

60. Harding CV, Song R. Phagocytic processing of exogenous particulate antigens by macrophages for presentation by class I MHC molecules. J Immunol. 1994;153(11):4925-4933.

61. Gallucci S, Lolkema M, Matzinger P. Natural adjuvants: endogenous activators of dendritic cells. Nat Med. 1999;5(11):1249-1255.

62. Allsopp CE, Plebanski M, Gilbert S, et al. Comparison of numerous delivery systems for the induction of cytotoxic T lymphocytes by immunization. Eur J Immunol. 1996;26(8):1951-1959.

63. Little SR. Reorienting our view of particle-based adjuvants for subunit vaccines. Proc Natl Acad Sci U S A. 2012;109(4):999-1000.

64. Baumgartner CK, Malherbe LP. Regulation of CD4 T-cell receptor diversity by vaccine adjuvants. Immunology. 2010;130(1) 16-22.

65. Moon JJ, Suh H, Li AV, Ockenhouse CF, Yadava A, Irvine DJ. Enhancing humoral responses to a malaria antigen with nanoparticle vaccines that expand Tfh cells and promote germinal center induction. Proc Natl Acad Sci U S A. 2012;109(4):1080-1085.

66. Puffer EB, Pontrello JK, Hollenbeck JJ, Kink JA, Kiessling LL. Activating B cell signaling with defined multivalent ligands. ACS Chem Biol. 2007;2(4):252-262.

67. Decuzzi P, Godin B, Tanaka T, et al. Size and shape effects in the biodistribution of intravascularly injected particles. J Control Release. 2010;141(3):320-327.

68. Chiappini C, Tasciotti E, Fakhoury JR, et al. Tailored porous silicon microparticles: fabrication and properties. Chemphyschem. 2010;11(5): 1029-1035.

69. Adriani G, de Tullio MD, Ferrari M, et al. The preferential targeting of the diseased microvasculature by disk-like particles. Biomaterials. 2012;33(22):5504-5513.

70. Kelly MG, Alvero AB, Chen R, et al. TLR-4 signaling promotes tumor growth and paclitaxel chemoresistance in ovarian cancer. Cancer Res. 2006;66(7):3859-3868.

71. Cresswell P, Ackerman AL, Giodini A, Peaper DR, Wearsch PA Mechanisms of MHC class I-restricted antigen processing and crosspresentation. Immunol Rev. 2005;207:145-157.

72. Schnorrer P, Behrens GM, Wilson NS, et al. The dominant role of CD8+ dendritic cells in cross-presentation is not dictated by antigen capture. Proc Natl Acad Sci U S A. 2006;103(28):10729-10734.

73. Pooley JL, Heath WR, Shortman K. Cutting edge: intravenous soluble antigen is presented to CD4 T cells by CD8- dendritic cells, but crosspresented to CD8 T cells by CD8+ dendritic cells. J Immunol. 2001; 166(9):5327-5330.

74. de Brito C, Tomkowiak M, Ghittoni R, Caux C, Leverrier Y, Marvel J. $\mathrm{CpG}$ promotes cross-presentation of dead cell-associated antigens by pre-CD8alpha+ dendritic cells [corrected]. J Immunol. 2011;186(3): 1503-1511.
75. Reece JC, Vardaxis NJ, Marshall JA, Crowe SM, Cameron PU. Uptake of HIV and latex particles by fresh and cultured dendritic cells and monocytes. Immunol Cell Biol. 2001;79(3):255-263.

76. Foged C, Brodin B, Frokjaer S, Sundblad A. Particle size and surface charge affect particle uptake by human dendritic cells in an in vitro model. Int J Pharm. 2005;298(2):315-322.

77. Rettig L, Haen SP, Bittermann AG, et al. Particle size and activation threshold: a new dimension of danger signaling. Blood. 2010;115(22): 4533-4541.

78. Gerelchuluun T, Lee YH, Lee YR, et al. Dendritic cells process antigens encapsulated in a biodegradable polymer, poly(D,L-lactideco-glycolide), via an alternate class I MHC processing pathway. Arch Pharm Res. 2007;30(11):1440-1446.

79. Tran KK, Shen H. The role of phagosomal $\mathrm{pH}$ on the size-dependent efficiency of cross-presentation by dendritic cells. Biomaterials. 2009;30(7):1356-1362.

80. Muro S, Garnacho C, Champion JA, et al. Control of endothelial targeting and intracellular delivery of therapeutic enzymes by modulating the size and shape of ICAM-1-targeted carriers. Mol Ther. 2008;16(8): 1450-1458.

81. Champion JA, Mitragotri S. Role of target geometry in phagocytosis. Proc Natl Acad Sci U S A. 2006;103(13):4930-4934.

82. Serda RE, Godin B, Blanco E, Chiappini C, Ferrari M. Multi-stage delivery nano-particle systems for therapeutic applications. Biochim Biophys Acta. 2011;1810(3):317-329.

83. Manolova V, Flace A, Bauer M, Schwarz K, Saudan P, Bachmann MF. Nanoparticles target distinct dendritic cell populations according to their size. Eur J Immunol. 2008;38(5):1404-1413.

84. Reddy ST, Rehor A, Schmoekel HG, Hubbell JA, Swartz MA. In vivo targeting of dendritic cells in lymph nodes with poly(propylene sulfide) nanoparticles. J Control Release. 2006;112(1):26-34.

85. Mottram PL, Leong D, Crimeen-Irwin B, et al. Type 1 and 2 immunity following vaccination is influenced by nanoparticle size: formulation of a model vaccine for respiratory syncytial virus. Mol Pharm. 2007;4(1): 73-84.

86. Rao DA, Forrest ML, Alani AW, Kwon GS, Robinson JR. Biodegradable PLGA based nanoparticles for sustained regional lymphatic drug delivery. J Pharm Sci. 2010;99(4):2018-2031.

87. Demento SL, Cui W, Criscione JM, et al. Role of sustained antigen release from nanoparticle vaccines in shaping the $\mathrm{T}$ cell memory phenotype. Biomaterials. 2012;33(19):4957-4964.

88. Fiore VF, Lofton MC, Roser-Page S, et al. Polyketal microparticles for therapeutic delivery to the lung. Biomaterials. 2010;31(5):810-817.

89. Yan W, Chen W, Huang L. Reactive oxygen species play a central role in the activity of cationic liposome based cancer vaccine. J Control Release. 2008;130(1):22-28.

90. Kanneganti TD, Lamkanfi M, Nunez G. Intracellular NOD-like receptors in host defense and disease. Immunity. 2007;27(4):549-559.

91. Schroder K, Tschopp J. The inflammasomes. Cell. 2010;140(6): 821-832.

92. Sharp FA, Ruane D, Claass B, et al. Uptake of particulate vaccine adjuvants by dendritic cells activates the NALP3 inflammasome. Proc Natl Acad Sci U S A. 2009;106(3):870-875.

93. Klaper R, Arndt D, Setyowati K, Chen J, Goetz F. Functionalization impacts the effects of carbon nanotubes on the immune system of rainbow trout, Oncorhynchus mykiss. Aquat Toxicol. 2010;100(2):211-217.

94. Salvador-Morales C, Flahaut E, Sim E, Sloan J, Green ML, Sim RB. Complement activation and protein adsorption by carbon nanotubes. Mol Immunol. 2006;43(3):193-201.

95. Farokhzad OC, Langer R. Impact of nanotechnology on drug delivery. ACS Nano. 27, 2009;3(1):16-20.

96. Kamaly N, Xiao Z, Valencia PM, Radovic-Moreno AF, Farokhzad OC. Targeted polymeric therapeutic nanoparticles: design, development and clinical translation. Chem Soc Rev. 2012;41(7):2971-3010.

97. Geijtenbeek TB, Gringhuis SI. Signalling through C-type lectin receptors: shaping immune responses. Nat Rev Immunol. 2009;9(7) $465-479$. 
98. Kunda NK, Somavarapu S, Gordon SB, Hutcheon GA, Saleem IY. Nanocarriers targeting dendritic cells for pulmonary vaccine delivery. Pharm Res. 2013;30(2):325-341.

99. Ebner S, Ehammer Z, Holzmann S, et al. Expression of C-type lectin receptors by subsets of dendritic cells in human skin. Int Immunol. 2004;16(6):877-887.

100. Beutner KR, Geisse JK, Helman D, Fox TL, Ginkel A, Owens ML. Therapeutic response of basal cell carcinoma to the immune response modifier imiquimod 5\% cream. J Am Acad Dermatol. 1999;41(6): 1002-1007.

101. Geissmann F, Jung S, Littman DR. Blood monocytes consist of two principal subsets with distinct migratory properties. Immunity. 2003; 19(1):71-82.

102. Manicassamy S, Ravindran R, Deng J, et al. Toll-like receptor 2-dependent induction of vitamin A-metabolizing enzymes in dendritic cells promotes $\mathrm{T}$ regulatory responses and inhibits autoimmunity. Nat Med. 2009;15(4):401-409.

103. Gringhuis SI, Geijtenbeek TB. Carbohydrate signaling by C-type lectin DC-SIGN affects NF-kappaB activity. Methods Enzymol. 2010;480: 151-164.

104. Palucka K, Ueno H, Zurawski G, Fay J, Banchereau J. Building on dendritic cell subsets to improve cancer vaccines. Curr Opin Immunol. 2010;22(2):258-263.

105. Latz E, Schoenemeyer A, Visintin A, et al. TLR9 signals after translocating from the ER to CpG DNA in the lysosome. Nat Immunol. 2004;5(2):190-198.

106. Ishii KJ, Coban $\mathrm{C}$, Kato $\mathrm{H}$, et al. A Toll-like receptor-independent antiviral response induced by double-stranded B-form DNA. Nat Immunol. 2006;7(1):40-48.

107. Stetson DB, Medzhitov R. Recognition of cytosolic DNA activates an IRF3-dependent innate immune response. Immunity. 2006;24(1): 93-103.

108. Gonzalez MJ, Plummer EM, Rae CS, Manchester M. Interaction of Cowpea mosaic virus (CPMV) nanoparticles with antigen presenting cells in vitro and in vivo. PLoS One. 2009;4(11):e7981.

109. Dalsgaard K, Uttenthal A, Jones TD, et al. Plant-derived vaccine protects target animals against a viral disease. Nat Biotechnol. 1997; 15(3):248-252.
110. Sisk EA, Robertson ES. Clinical implications of human papillomavirus infection. Front Biosci. 2002;7:e77-e84.

111. Block TM, Mehta AS, Fimmel CJ, Jordan R. Molecular viral oncology of hepatocellular carcinoma. Oncogene. 2003;22(33):5093-5107.

112. Young LS, Murray PG. Epstein-Barr virus and oncogenesis: from latent genes to tumours. Oncogene. 2003;22(33):5108-5121.

113. Hall FL, Levy JP, Reed RA, et al. Pathotropic targeting advances clinical oncology: tumor-targeted localization of therapeutic gene delivery. Oncol Rep. 2010;24(4):829-833.

114. Gordon EM, Hall FL. Noteworthy clinical case studies in cancer gene therapy: tumor-targeted Rexin-G advances as an efficacious anti-cancer agent. Int J Oncol. 2010;36(6):1341-1353.

115. Aslanidi GV, Rivers AE, Ortiz L, et al. High-efficiency transduction of human monocyte-derived dendritic cells by capsid-modified recombinant AAV2 vectors. Vaccine. 2012;30(26):3908-3917.

116. Rosenberg SA, Yang JC, Restifo NP. Cancer immunotherapy: moving beyond current vaccines. Nat Med. 2004;10(9):909-915.

117. Koido S, Hara E, Homma S, et al. Cancer vaccine by fusions of dendritic and cancer cells. Clin Dev Immunol. 2009;2009:657369.

118. Li M, Davey GM, Sutherland RM, et al. Cell-associated ovalbumin is cross-presented much more efficiently than soluble ovalbumin in vivo. J Immunol. 2001;166(10):6099-6103.

119. Small EJ, Fratesi P, Reese DM, et al. Immunotherapy of hormonerefractory prostate cancer with antigen-loaded dendritic cells. J Clin Oncol. 2000;18(23):3894-3903.

120. Shore ND, Mantz CA, Dosoretz DE, et al. Building on sipuleucel-T for immunologic treatment of castration-resistant prostate cancer. Cancer Control. 2013;20(1):7-16.

121. Serda RE, MackA, Pulikkathara M, et al. Cellular association and assembly of a multistage delivery system. Small. 2010;6(12):1329-1340.

122. Serda RE, Gu J, Bhavane RC, et al. The association of silicon microparticles with endothelial cells in drug delivery to the vasculature. Biomaterials. 2009;30(13):2440-2448.

123. Serda RE, Mack A, van de Ven AL, et al. Logic-embedded vectors for intracellular partitioning, endosomal escape, and exocytosis of nanoparticles. Small. 2010;6(23):2691-2700.
International Journal of Nanomedicine

\section{Publish your work in this journal}

The International Journal of Nanomedicine is an international, peerreviewed journal focusing on the application of nanotechnology in diagnostics, therapeutics, and drug delivery systems throughout the biomedical field. This journal is indexed on PubMed Central, MedLine, CAS, SciSearch $\AA$, Current Contents ${ }^{\circledR} /$ Clinical Medicine,

\section{Dovepress}

Journal Citation Reports/Science Edition, EMBase, Scopus and the Elsevier Bibliographic databases. The manuscript management system is completely online and includes a very quick and fair peer-review system, which is all easy to use. Visit http://www.dovepress.com/ testimonials.php to read real quotes from published authors. 